\title{
Evaluation of a Web-based Self-learning System for Lifestyle Improvement
}

\author{
Masashi Sugano and Rieko Araki \\ School of Comprehensive Rehabilitation \\ Osaka Prefecture University \\ 3-7-30, Habikino, Habikino-shi \\ Osaka 583-8555, Japan \\ Email: sugano@rehab.osakafu-u.ac.jp
}

\author{
Naomi Aiba \\ Project of Nutritional Education Program \\ National Institute of Health and Nutrition \\ 1-23-1, Toyama, Shinjuku-ku \\ 162-8636, Tokyo, Japan \\ Email: naomi@nih.go.jp
}

\begin{abstract}
In this study we examine the web-based "Selflearning System for Preventing Lifestyle-related Disease" currently being developed by the National Institute of Health and Nutrition in order to determine areas for improvement, making the system easier to use. College students of the national registered dietitian training course adopted the roles of learners and supporters in the system and we analyzed their system use history and obtained feedback concerning system use via a questionnaire. There were many requests for the ability to use the system through a mobile phone. Moreover, it became clear that the data input methods involving, for example, calorie acquisition, need to be simplified.
\end{abstract}

Index Terms-nutrition instruction, lifestyle-related disease, self-learning system, behaviour exchange, web-based education

\section{INTRODUCTION}

The health care system is beginning to embrace the concept of education in medicine and health-related topics via the Internet for promoting the self-management of patients with chronic and other diseases [1], [2], [3], [4], [5], [6]. The use of such a web-based system by diabetic patients is one such example, where the patient helps with self-management of the disease by inputting various data regarding blood sugar management, meals, exercise, medication and so forth into the system. The patient can then receive advice and medical and emotional support from healthcare professionals via the web without waiting for the next consultation at hospital. Such a system has the desirable application of being constantly accessible, and being non-real time in nature does not involve realtime applications such as teleconferencing or video telephony, and thus keeps the costs of system use low [7], [8], [9]. Since communication between multiple supporters and patients in the system would be difficult by email, for example, tracing back and supporting past communications, a web-based system is the most suitable way to realize the target self-learning system [10].

The web-based system for lifestyle improvement called the "Self-learning System for Lifestyle Diseases Prevention" created by the National Institute of Health and Nutrition, which is the object of evaluation in this study, is in the development stage, and improvements to the system for ease

Permission to make digital or hard copies of all or part of this work for personal or classroom use is granted without fee provided that copies are not made or distributed for profit or commercial advantage and that copies bear this notice and the full citation on the first page. To copy otherwise, to republish, to post on servers or to redistribute to lists, requires prior specific permission and/or a fee.

PERVASIVEHEALTH 2008, 30 Jan - 1 Feb. Tampere, Finland

Copyright $\odot 2008$ ICST 978-963-9799-15-8

DOI 10.4108/ICST.PERVASIVEHEALTH2008.2503

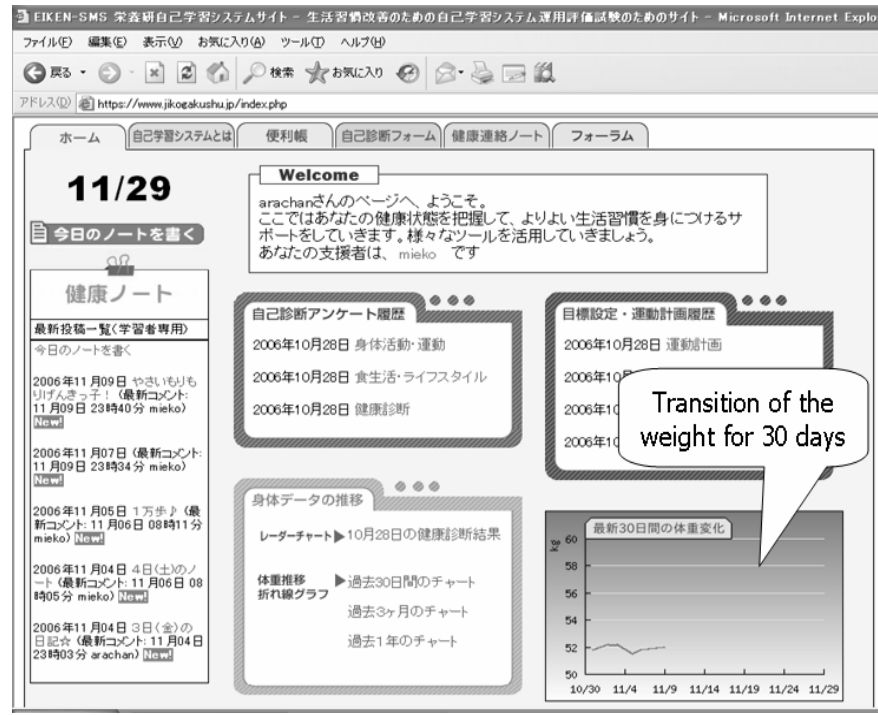

Fig. 1. Screenshot of Self-learning System

of use and learning effect are expected. The purpose of this study was to determine such system improvements.

The remainder of the paper is as follows. Section 2 presents the outline of self-learning system and method of investigation. The results are described in Section 3. In Section 4, we describe the consideration and future work.

\section{METHOD}

\section{A. Outline of the self-learning system}

Those users of the system who are practicing selfmanagement via the web are called learners and those who help the learners are called supporters. The system has three main components, as shown in Fig. 2. The first is a selfassessment questionnaire that is used by the learner to understand the problem in his lifestyle. The second is a set of guidelines which state the target and plan for improving his lifestyle. The learner, receiving assistance from a supporter based on the results of the self-assessment, actively creates the lifestyle plan himself. The third is a health information note which is the most important component of the system (Fig.3). The health information note is where the learner fills in freely the implementation states concerning, for example, daily 


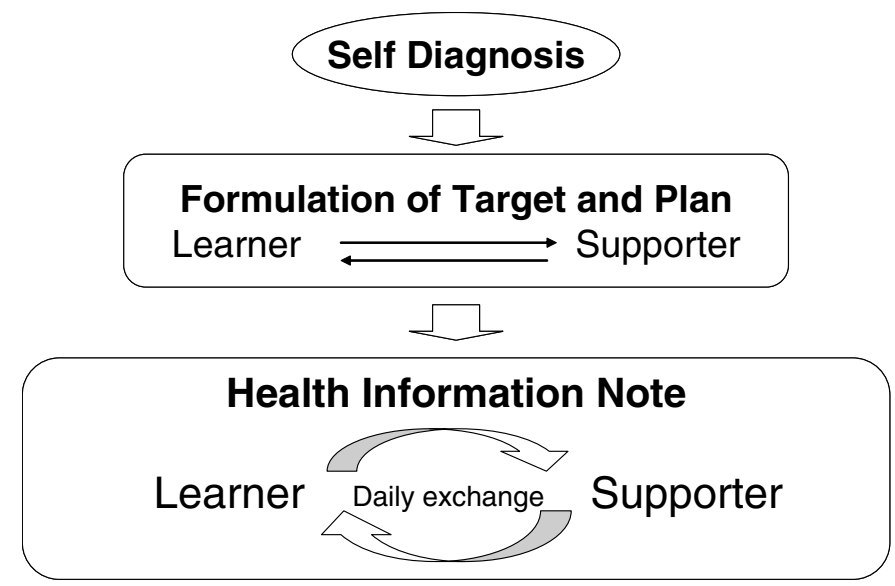

Fig. 2. Outline of Self-lerning System

meals, exercise, how the plan is working, and the learner's ideas and feelings. In response, the supporter enters a comment in the form of advice, encouragement and so forth on the health information note. Behavior modification of the learner toward a better lifestyle is considered to be enhanced through the exchange of the health information note on this web-based system. Moreover, a bulletin board for learners is available in this system so they can exchange ideas and opinions and provide mutual encouragement and support (Fig. 4).

\section{B. Method of investigation and evaluation}

Twenty-three students belonging to the School of Comprehensive Rehabilitation of Osaka Prefectural College of Nursing agreed to participate in this research and try using the webbased system. The trial period ran from September 17, 2006 to November 10, 2006. The participants were classified into

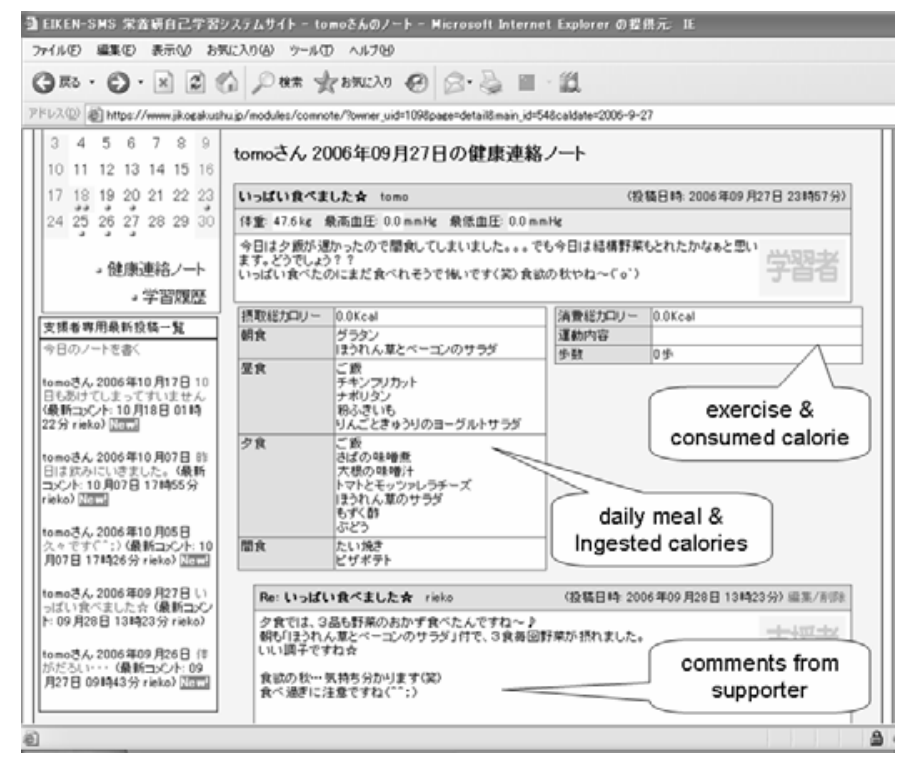

Fig. 3. Health Information Note: A learner records exercise, the calorie taken in, etc. in this health information note every day. Then, a supporter returns a comment to these information.

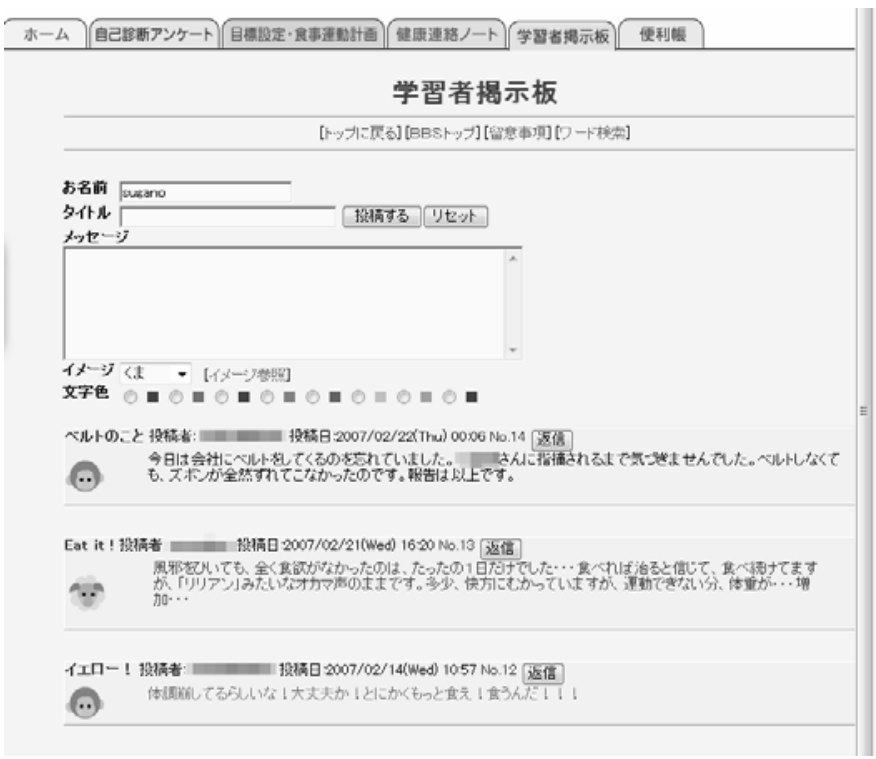

Fig. 4. Bulletin Board for Learners: Learners can exchange ideas and opinions and provide mutual encouragement and support.

two groups: learners $(n=18)$ and supporters $(n=5)$, and then further divided into five groups comprising 1 supporter to 3-4 learners.

After the trial period, we evaluated the system based on questionnaire responses and the history of system use. The questionnaire was open-ended and consisted of 5 items for which the respondents reported their evaluation of the system in terms of merits and demerits, satisfaction and dissatisfaction and possible improvements. From the use history, we determined the frequency of use, the duration of use, and so on.

\section{RESULTS}

Analysis of the system use history revealed that learners accessed the system 170 times and supporters accessed it 131 times. In terms of duration of use, 10 or less minutes accounted for $80 \%$ or more for both learners and supporters (Fig.5). Thus, the time burdens for using this system for most users were little. However, $15 \%$ of learners have spent the time for 10 minutes or more, and they may feel daily operation for the burden. Moreover, the system use time zone tended to be concentrated at evening times and nighttimes (Fig. 6). That is, learners accessed the site to input data about meals and exercise before sleeping.

Moreover, for questionnaire responses, we found strong correlations between system use frequency and confidence in continued system use $[r=0.736(p<0.001)]$, between lightness of the burden of system use and confidence in continued use $[r=0.716(p<0.001)]$, and between frequency of use and satisfaction with system use $[r=0.692(p<0.01)]$. Further, there was the suggestion for the addition of a function that calculates the calorie acquisition of meals as an improvement to data entry. 


\section{Consideration And Future Work}

Overall, system users were able to access the web-based system with sufficient convenience and for comparatively short times. It therefore seems that the use of a web-based system has a role in helping to improve lifestyle. However, for those

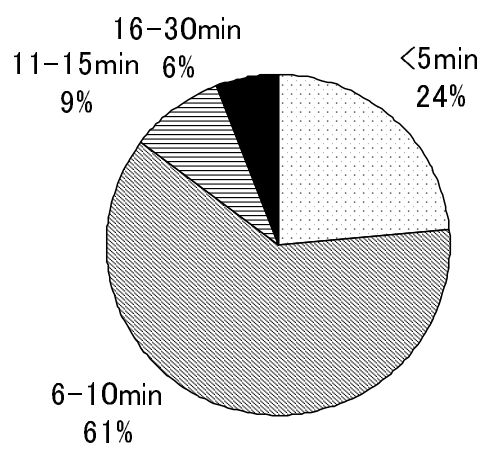

(a) Learner

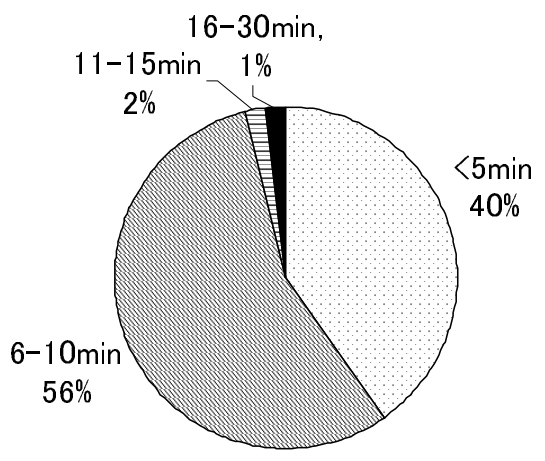

(b) Supporter

Fig. 5. Duration of System Use: 10 or less minutes accounted for $80 \%$ or more for both learners and supporters. However, $15 \%$ of learners have spent the time for 10 minutes or more, and they may feel daily operation for the burden.

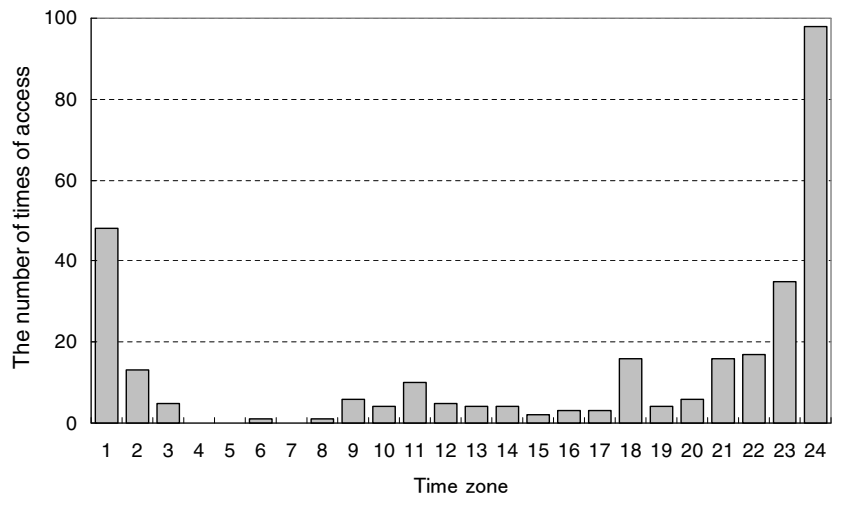

Fig. 6. System Use Timezone: Many learners had accessed the system at midnight. This is because the learner needs to input before sleeping behavior record and the calorie taken in of the day. participants who found using a personal computer a burden or who were too busy to use it, frequency of use dropped. Therefore, we propose the following improvements for such persons in order to promote their continued usage. The first is to make access possible from mobile phones, which is a more familiar tool than a personal computer for some people. This would enable the health information note to be updated daily from this convenient device [11]. Moreover, we consider it important to reduce the burden of the learner without knowledge of nutrition by including in the system a calorie calculator to determine the calorie acquisition of their meals.

In this evaluation, the students participated outside term time and it was found that by using this system frequent communication providing nutritional instruction could be continued. This suggests that the system can be applied for selfmanagement of lifestyle in persons of middle or advanced age. However, it must be considered that the awareness of healthcare as well as the affinity to Internet usage differs among generations. Therefore, we need to investigate whether this system shows a similar lifestyle effect among persons of middle or advanced age. Furthermore, the present system is designed on the premise that one dietitian takes the role of supporter, but we should clarify whether this system is applicable to intervention provided by other healthcare professionals and to the use of multiple supporters.

Currently we are focusing our attention on whether the system can incorporate a sensor network. We consider that a more useful system can be built by enabling it to collect measurement data via, for examples scales or a sphygmomanometer, through a sensor network, without requiring the use of a personal computer (Fig. 7). We consider that ZigBee based on IEEE 802.15.4 is most suitable as a protocol for building such a home sensor network [12], [13]. After the selflearning system combined with such a home sensor network, we are going to express this anew.

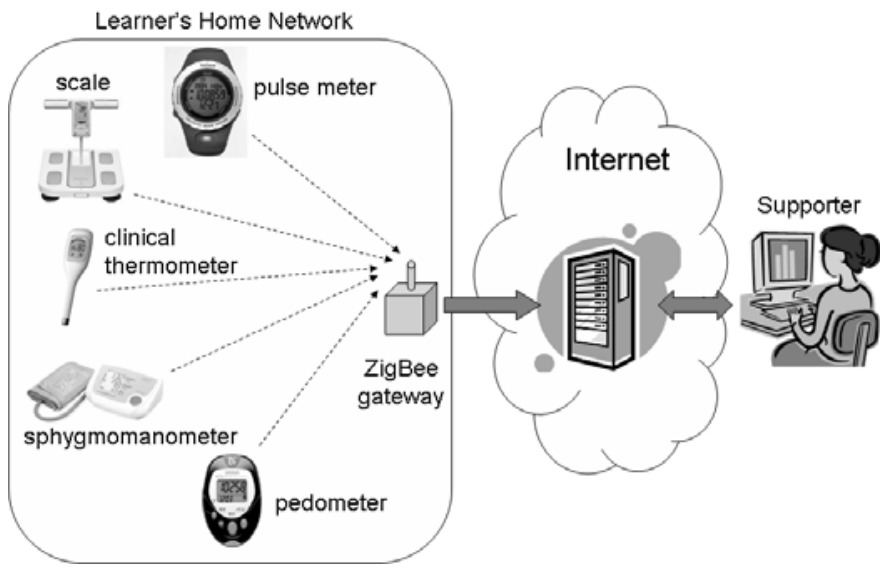

Fig. 7. Data collection by ZigBee based learner's home network: By using a wireless home network, a learner's burden is mitigable by collecting the vital signs measured by various apparatus, without using PC. 


\section{ACKNOWLEDGMENT}

This research was supported in part by the research fund distributed by the Dean of the School of Comprehensive Rehabilitation, Osaka Prefecture University, Japan.

\section{REFERENCES}

[1] C. Giacomozzi, D. Cordella, M. Rogante, S. Scattareggia, R. Magni, M. Zampolini, M. B. Guitart, S. Lisbroukx, and B. Huijgen, "A European e-learing experience in upper limb telerehabilitation," in Proceedings of IASTED International Conference on Telehealth, Jul. 2006, pp. 108-113.

[2] K. Brauchli, R. Jagilly, H. Oberli, K. D. Kunze, G. Phillips, N. Hurwitz, and M. Oberholzer, "Telepathology on the Solomon Island - two years' experience with a hybrid web- and e-mail based telepathology system," Journal of Telemedicine and Telecare, vol. 10, no. Suppl. 1, pp. 14-17, 2004.

[3] G. Andersson, J. Bergstrom, F. Hollandare, P. Carlbring, V. Kaldo, and L. Ekselius, "Internet-based self-help for depression: randomised controlled trial," British Journal of Psychiatry, vol. 187, pp. 456-461, 2005.

[4] J. D. Ralston, D. Revere, L. S. Robins, and H. I. Goldberg, "Patients' experience with a diabetes support programme based on an interactive electronic medical record: qualitative study," $B M J$, vol. 328, pp. 1159 1162, May 2004.

[5] G. Eysenbach, J. Powell, M. Englesakis, C. Rizo, and A. Stern, "Health related virtual communities and electronic support groups: systematic review of the effects of online peer to peer interactions," BMJ, vol. 328, pp. 1166-1171, May 2004.

[6] L. Wilson, L. McAllister, J. Atkinson, and P. Sefton, "Internet based telehealth in speech pathology: results of preliminary trials," in Proceedings of IASTED International Conference on Telehealth, Jul. 2006, pp. 131-136.

[7] L. Reimer, L. Liu, and I. Henderson, "Beyond videoconference: A literature review of store-and-foreward applications in telehealth," in Proceedings of IASTED International Conference on Telehealth, Jul. 2006, pp. 125-130.

[8] S. H. Walsh, "The clinician's perspective on electronic health records and how the can affect patient care," BMJ, vol. 328, pp. 1184-1187, May 2004.

[9] M. A. Loane, S. E. Bloomer, R. Corbett, D. J. Eedy, N. Hicks, H. E. Lotery, C. Mathews, J. Paisley, K. Steele, and R. Wootton, "A comparison of real-time and store-and-forward teledermatology: a costbenefit study," British Journal of Dermatology, vol. 143, pp. 1241-1247, 2000.

[10] B. G. Danaher, S. M. Boles, L. Akers, J. S. Gordon, and H. H. Severson, "Defining participant exposure measures in web-based health behavior change programs," Journal of Medical Internet Research, vol. 8, no. 3, p. e15, Aug. 2006.

[11] C. C. Tsai, G. Lee, F. Raab, G. J. Norman, T. Sohn, W. G. Griswold, and K. Patrick, "Usability and feasibility of PmEB: A mobile phone application for monitoring real time caloric balance," Mobile Networks and Applications, vol. 12, pp. 173-184, Jun. 2007.

[12] A. G. Ruzzelli, R. Jurdak, G. M. P. O'Hare, and P. V. D. Stok, "Energy-efficient multi-hop medical sensor networking," in Proceedings of ACM International Workshop on Systems and Networking Support for Healthcare and Assisted Living Environments, Jun. 2007, pp. 37-42.

[13] U. Varshney, "Pervasive healthcare and wireless health monitoring," Mobile Networks and Applications, vol. 12, pp. 113-127, Jun. 2007. 